\title{
Effect of thermal pretreatment and nanosilica addition on limestone performance at Calcium-Looping conditions for Thermochemical Energy Storage of Concentrated Solar Power
}

Jose Manuel Valverde*a, Manuel Barea-López ${ }^{\mathrm{b}}$, Antonio Perejón ${ }^{\mathrm{b}, \mathrm{c}}$, Pedro E. Sánchez-Jiménez ${ }^{\mathrm{b}}$, Luis A. Pérez-Maqueda ${ }^{\mathrm{b}}$

${ }^{a}$ Faculty of Physics, University of Seville, Avenida Reina Mercedes s/n, 41012 Sevilla, Spain.

${ }^{\text {b}}$ Instituto de Ciencia de Materiales de Sevilla (C.S.I.C.-Universidad de Sevilla). C. Américo Vespucio 49, Sevilla 41092. Spain.

cDepartamento de Química Inorgánica, Facultad de Química, Universidad de Sevilla, Sevilla 41071, Spain.

*Corresponding author: jmillan@us.es

\begin{abstract}
The share of renewable energies is rapidly growing partly in response to the urgent need of mitigating $\mathrm{CO}_{2}$ emissions from fossil fuel power plants. However, cheap and efficient large-scale energy storage technologies are not yet available to allow for a significant penetration of renewable energies into the grid. Recently, it has been proposed a potentially low-cost and efficient thermochemical energy storage (TCES) system based on the integration of the Calcium Looping $(\mathrm{CaL})$ process into Concentrated Solar Plants (CSP). The CaL process relies on the multicycle carbonation/calcination of $\mathrm{CaO}$, which can be derived from calcination of widely available, cheap and non-toxic natural limestone $\left(\mathrm{CaCO}_{3}\right)$. This work explores the effect on the multicycle activity of limestone derived $\mathrm{CaO}$ of thermal pretreatment under diverse atmospheres and the addition of nanosilica, which would expectedly hinder $\mathrm{CaO}$ grain sintering. Importantly, optimum CaL conditions for CSP energy storage differ radically from those used in the application of the $\mathrm{CaL}$ process for $\mathrm{CO}_{2}$ capture. Thus,
\end{abstract}


calcination should be ideally carried out under low $\mathrm{CO}_{2}$ partial pressure at moderate temperature (below $750^{\circ} \mathrm{C}$ ) whereas $\mathrm{CO}_{2}$ concentration and temperature should be high for carbonation in order to maximize thermoelectric efficiency. When subjected to carbonation/calcination cycles at these conditions, limestone performance is critically dependent on the type of pretreatment. Our results indicate that the multicycle $\mathrm{CaO}$ activity is correlated with the size of the particles and the $\mathrm{CaO}$ pore size distribution. Thus, $\mathrm{CaO}$ activity is impaired as particle size is increased and/or $\mathrm{CaO}$ pore size is decreased. These observations suggest that pore plugging poses a main limitation to the multicycle performance of limestone derived $\mathrm{CaO}$ at the optimum $\mathrm{CaL}$ conditions for TCES in CSP, which is supported by SEM analysis. Strategies to enhance the performance of natural limestone at these conditions should be therefore oriented towards minimizing pore plugging rather than $\mathrm{CaO}$ grain sintering, which stands as the main limitation at $\mathrm{CaL}$ conditions for $\mathrm{CO}_{2}$ capture.

\section{Introduction}

The deployment of renewable energies, mainly solar and wind, has risen exponentially in the last years. In the $21^{\text {th }}$ Conference of Parties (COP21), countries agreed to limit the increase in the global surface temperature below $2.0{ }^{\circ} \mathrm{C}$ in $2100 .{ }^{1}$ For achieving such ambitious goal, power production from renewable energy sources must be massively incorporated into the grid in the short to medium term. To this end, it is mandatory to develop large-scale energy storage technologies that allow overcoming the inherently intermittent nature of the principal renewable energy sources (solar and wind). Due to the huge-scale of the problem and to be competitive against fossil fuels, these new energy storage technologies must be efficient, affordable and environmental friendly.

Concentrated solar thermal power (CSP) is considered as a promising renewable energy technology to replace fossil fuel plants for grid power production as it offers the possibility of large scale electricity generation with potentially cheap thermal energy storage. $^{2-4}$ Conventional coal fired power plants (CFPP) burn coal to generate a high temperature and high pressure water steam, which expands into a turbine to produce mechanical work according to a Rankine cycle. The main difference between conventional CFPP and CSP is that, in the latter, the boiler is replaced by a heliostats 
distributed system and a central tower in the case of CSP with tower technology that concerns us in the present paper. Heliostats concentrate solar irradiation in a central receiver at the top of the tower where heat is transferred to a fluid for generating electricity. Currently, a number of CSP demonstration plants are under operation worldwide incorporating thermal energy storage to generate electricity in the absence of direct solar irradiation. When available, direct solar irradiation is used to heat a socalled HTF (heat transfer fluid) consisting of a mixture of molten salts with high heat capacity. The solar salt is carried to a hot salts tank where energy is stored in the form of sensible heat with an energy density near $0,8 \mathrm{GJ} / \mathrm{m}^{3} .5$ On demand, the hot salt is circulated to a steam generator system where heat is transferred to water vapour while the cold salt is stored in a cold salts tank. However, the use of molten salts poses serious inconveniences that hinder the competitiveness of CSP with this type of energy storage. One of them is a limitation of the salt upper temperature due to its decomposition near $600^{\circ} \mathrm{C}$, which does not allow to achieve sufficiently high thermo-electric efficiencies as compared with fossil fuels. Another relevant issue is the high solidification point of the molten salts (between $120^{\circ} \mathrm{C}$ and $220^{\circ} \mathrm{C}$ ), which makes it necessary to keep the salts at temperatures above these values leading to important heat losses especially during the night hours in desert zones at high altitude where CSP technology allocation is more appropriate. In addition, molten salts are very corrosive, which requires the installation of costly materials for pipes and valves. Solar salts commonly considered for thermal energy storage (TES) are the binary $\mathrm{KNO}_{3}-\mathrm{Na} / \mathrm{NO}_{3}$ system, the ternary systems $\mathrm{NaNO}_{2}$ $\mathrm{NaNO}_{3}-\mathrm{KNO}_{3}$ and the two ternary additive systems $\mathrm{Ca}\left(\mathrm{NO}_{3}\right)_{2}-\mathrm{NaNO}_{3}-\mathrm{KNO}_{3}$ and $\mathrm{LiNO}_{3}-\mathrm{KNO}_{3}-\mathrm{NaNO}_{3}$. A comprehensive and concise review on TES systems based on molten salts including their thermophysical properties and novel salt formulations may be found in refs [6-9].

An alternative energy storage system to thermal energy storage in the form of sensible heat is Thermochemical Energy Storage (TCES), currently under R\&D. ${ }^{10-11}$ Essentially, TCES consists of using the potentially high temperatures attainable in the solar receiver to carry out an endothermic chemical reaction. The reaction by-products are stored individually and, when energy is needed, they are brought together to drive the exothermic reverse reaction. Some important advantages of TCES versus sensible heat storage in molten salts are the possibility of storing energy permanently with a 
relatively high density and the potentially high efficiencies attainable by properly selecting the reacting systems at the relevant operation temperatures. ${ }^{12}$

Searching for a reversible reaction that better suits the characteristics of CSP plants with tower technology is a key issue. The materials to be used should allow affordable operation costs and the turning point of the reversible reaction must fit into the range of operating temperatures. ${ }^{13}$ In this context, the Calcium Looping (CaL) process satisfies the requirements for a feasible TCES integration in CSP with tower technology. ${ }^{14}$ The $\mathrm{CaL}$ process is based on the carbonation/calcination reaction of $\mathrm{CaO}$ (eq.1).

$$
\mathrm{CaO}_{(\mathrm{s})}+\mathrm{CO}_{2(\mathrm{~g})} \rightleftarrows \mathrm{CaCO}_{3(\mathrm{~s})} ; \Delta \mathrm{H}_{\mathrm{r}}^{0}=-178 \mathrm{~kJ} / \mathrm{mol}
$$

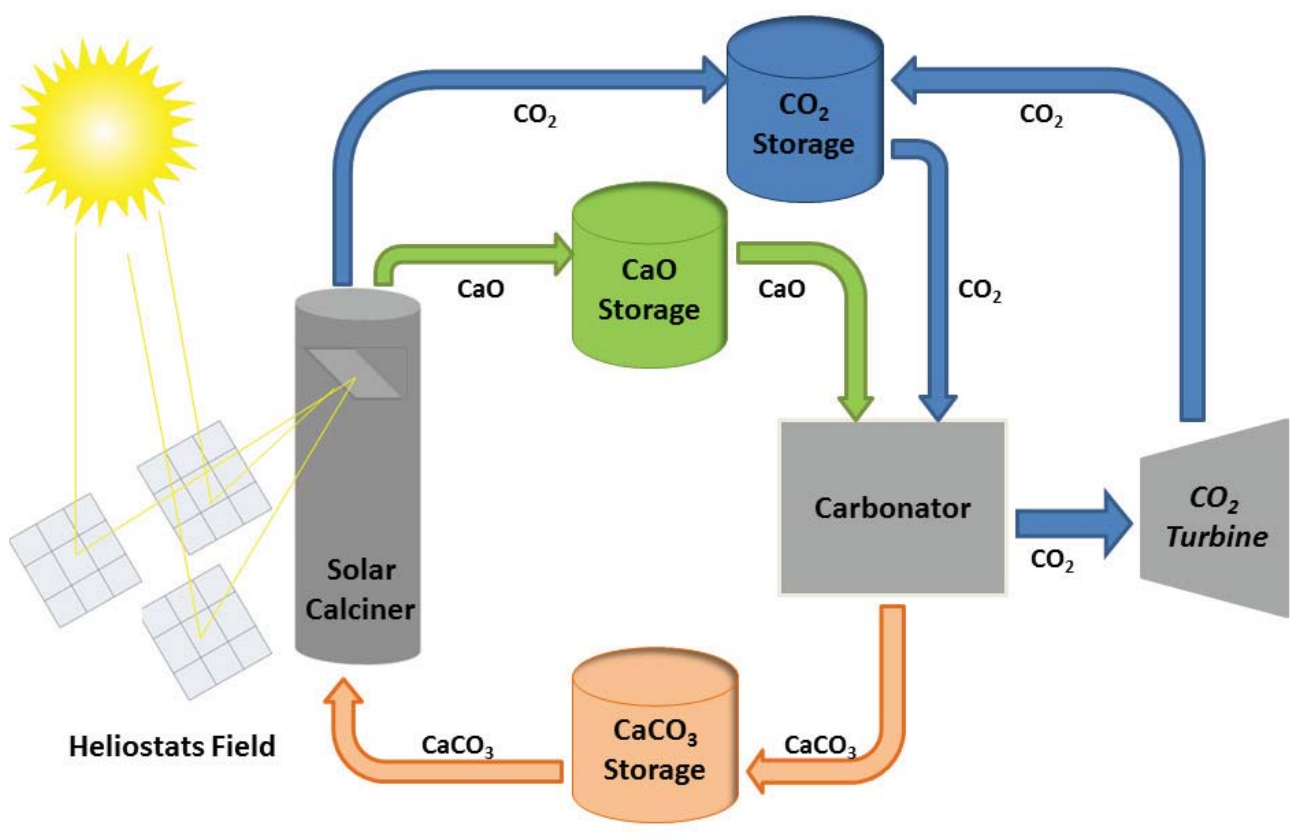

Fig. 1. Flow diagram of the CSP-CaL integration for Thermochemical Energy Storage 
The use of the CaL process for TCES in CSP has many potential advantages such as the wide availability of limestone (almost $100 \% \mathrm{CaCO}_{3}$ ), its low cost, non-toxicity, and the high energy density attainable from the reaction enthalpy $\left(\sim 3.2 \mathrm{GJ} / \mathrm{m}^{3}\right){ }^{13}$ A recently proposed scheme for the CaL- CSP integration leads to a potentially high thermoelectric efficiency using a closed $\mathrm{CO}_{2}$ cycle for the carbonation reaction to generate electric power through a Brayton cycle as shown in the flow diagram of Fig. $1 .{ }^{15}$ In this integration scheme, concentrated solar energy is used to carry out the calcination reaction. The $\mathrm{CO}_{2}$ and $\mathrm{CaO}$ streams stemming from calcination are passed through a heat exchanger network to extract their sensible heat after which they are stored at ambient temperature. $\mathrm{CaO}$ solids are circulated into a solids reservoir whereas the $\mathrm{CO}_{2}$ gas stream is stored in reasonably sized tanks under high pressure ( $\sim 75$ bar) at supercritical conditions by means of intercooling compression. Thus, besides of sensible and thermochemical energy storage, this integration includes energy storage also in the form of compressed gas (with a round trip efficiency of about $67 \%$ by using a compression-expansion train). On the other hand, a main advantage of the CSP-CaL integration is that the reactants can be stored at ambient temperature as opposed to molten salts, which must be kept always at temperatures over $\sim 200^{\circ} \mathrm{C}$ to avoid solidification. Thermochemical stored energy is released in the carbonator on demand through the exothermic carbonation reaction. Thus, the $\mathrm{CO}_{2}$ exiting the carbonator at high temperature over the stoichiometric ratio is used as heat gas carrier to generate electric power by means of a gas turbine in a closed circuit. Carbonation may be carried out at high temperature $\left(>850^{\circ} \mathrm{C}\right)$ under high $\mathrm{CO}_{2}$ partial pressure to maximize the thermoelectric efficiency, which allows overcoming current temperature limits (T 550$600^{\circ} \mathrm{C}$ ) in commercial CSP plants wherein heat is stored in molten salts. Thus, predicted efficiencies for this integration (above $\sim 45 \%$ ) are significantly higher than the efficiency achieved by using sensible heat storage in molten salts. The interested reader is referred to ref. [15], where a detailed energy integration study based on pinch-analysis methodology has been presented.

The multicycle $\mathrm{CaO}$ conversion (ratio of mass of $\mathrm{CaO}$ carbonated to initial mass in each cycle) in short residence times plays a relevant role on the CSP-CaL integration as any significant decay of it with the number of cycles would hinder the global plant efficiency. ${ }^{15-16} \mathrm{~A}$ further important issue to consider for storing the maximum amount of energy during solar hours is that the calcination reaction should be completely achieved 
as fast as possible and at the lowest possible temperature. From a techno-economical point of view, lowering the calcination temperature and shortening the reaction time would allow the use of relatively cheap volumetric receivers based of low cost metal alloys capable of working at temperatures up to $800^{\circ} \mathrm{C} .{ }^{17}$ Thus, it has been shown that the use of high thermal conductivity gases such as helium or super-heated steam would enhance calcination at reduced temperatures (below $750^{\circ} \mathrm{C}$ ). ${ }^{18}$ These gases could be separated from the $\mathrm{CO}_{2}$ released in the calcination reaction to store it in compression tanks as pure as possible whereas He or super-heated steam is recirculated to be reused in the calcination reaction. The $\mathrm{CO}_{2} / \mathrm{H}_{2} \mathrm{O}$ gas mixture could be separated by steam condensers, ${ }^{19}$ whereas the $\mathrm{CO}_{2} / \mathrm{He}$ mixture is separable by selective membranes. ${ }^{20}$

In the last years, the $\mathrm{CaL}$ process has acquired a great relevance as a $2^{\text {nd }}$ generation technology for capturing $\mathrm{CO}_{2}$ emissions from fossil fuel power plants. ${ }^{21-22}$ In this process, the capture of $\mathrm{CO}_{2}$ from flue gases is performed by means of the carbonation reaction of $\mathrm{CaO}$ (eq.1). The gas-solid reaction takes place in a high temperature fluidized bed reactor (around $650^{\circ} \mathrm{C}$ ) where the post-combustion flue gas containing a $\mathrm{CO}_{2}$ concentration near $15 \%$ vol. is used to fluidize a bed of $\mathrm{CaO}$ solids at atmospheric pressure. The partially carbonated $\mathrm{CaO}$ particles are then transported into a second reactor (calciner) where $\mathrm{CaO}$ is regenerated by calcination at high $\mathrm{CO}_{2}$ partial pressure and high temperatures $\left(\sim 950^{\circ} \mathrm{C}\right) . \mathrm{CaO}$ particles regenerated from calcination are carried again to the carbonator to be used in a new cycle. It must be remarked that calcination under high $\mathrm{CO}_{2}$ vol concentration is a must in the $\mathrm{CaL}$ process for $\mathrm{CO}_{2}$ capture in order to avoid its dilution before extracting it from the calciner for compression and storage afterwards. On the other hand, carbonation for $\mathrm{CO}_{2}$ capture is carried out at relatively low $\mathrm{CO}_{2}$ vol concentration. Under these harsh conditions the multicycle conversion of natural limestone derived $\mathrm{CaO}$ suffers a drastic drop in just a few cycles. Numerous studies have been carried out on the use of additives or other techniques such as thermal pretreatment to mitigate the decay of the multicycle $\mathrm{CaO}$ activity, which is mainly caused by $\mathrm{CaO}$ grain sintering in the calcination stage. ${ }^{23-24}$ Thus, the $\mathrm{CaO}$ multicycle conversion in short residence times at $\mathrm{CaL}$ conditions for $\mathrm{CO}_{2}$ capture could be stabilized by the addition of nanostructured $\mathrm{SiO}_{2}{ }^{25-26}$ and thermal pretreatment, ${ }^{27}$ which mitigate $\mathrm{CaO}$ sintering.

In the present work, natural limestone samples have been thermally pretreated by calcination under different atmospheres and the effect of thermal pretreatment on 
their multicycle performance at CaL conditions for CSP energy storage has been studied for the first time to our knowledge. The effect of the addition of nanosilica on the multicycle $\mathrm{CaO}$ conversion at these conditions has been also newly tested. Although these techniques have been already employed in previous works ${ }^{25-27}$ to observe their effect on the multicycle $\mathrm{CaO}$ conversion at $\mathrm{CaL}$ conditions for $\mathrm{CO}_{2}$ capture, it must be remarked that $\mathrm{CaL}$ conditions for CSP energy storage differ radically from those used to capture $\mathrm{CO}_{2}$, which may have an important effect yet unexplored on the role of the used techniques to enhance the multicycle $\mathrm{CaO}$ activity.

\section{Materials and methods}

High purity natural limestone $\left(>99 \% \mathrm{CaCO}_{3}\right)$ from Matallagar quarry (Pedrera, Seville, Spain) has been used in our work as $\mathrm{CaO}$ precursor. Samples from different batches received (labeled as A and B) were employed with diverse concentration of impurities as seen from X-Ray fluorescence (XRF) measurements (Table 1) conducted using an Axios (PANalytical) spectrometer. Even though both samples exhibit a very high $\mathrm{Ca}$ content, the sample from batch A shows a larger amount of impurities. It is remarkable the relatively higher concentration of $\mathrm{Mg}$ in sample $\mathrm{A}$, whose presence can be attributed to dolomite usually found as impurity in natural limestone. As reported in previous studies, ${ }^{28}$ the multicycle $\mathrm{CaL}$ activity of $\mathrm{CaO}$ derived from dolomite is improved as compared to $\mathrm{CaO}$ derived from limestone. However, the presence of dolomite by a small amount in Limestone A is not expected to yield a significant improvement of performance.

Table 1. Elemental composition of natural limestone samples A and B from different batches used in our work as measured by XRF.

\begin{tabular}{|l|c|c|c|c|c|c|c|c|c|c|c|}
\hline Elements & Ca & Mg & Al & Si & Fe & Na & K & P & S & Sr & Mn \\
\hline $\begin{array}{l}\text { Limestone } \\
\text { A (wt\%) }\end{array}$ & 39,53 & 0,15 & 0,02 & 0,14 & 0,07 & 0,02 & 0,02 & 0,02 & 0,02 & 0,01 & 0,02 \\
\hline $\begin{array}{l}\text { Limestone } \\
\text { B (wt\%) }\end{array}$ & 40,04 & 0,09 & - & 0,02 & 0,01 & - & - & 0,01 & 0,02 & 0,01 & - \\
\hline
\end{tabular}


In order to carry out the thermal treatments, a setup was built to calcine the samples under different gases, including super-heated steam, in a controlled way. Thus, besides of superheated-steam (SHS), thermal pretreatments were carried out under $\mathrm{N}_{2}$, $\mathrm{He}$ and $\mathrm{CO}_{2}$ atmospheres. Precalcinations were accomplished in a tube furnace and the hot junction of a thermocouple was placed on the top of the sample to accurately control the temperature during the calcination process (Figure 2). The temperature was continuously monitored while the thermal pretreatment took place. When calcination was carried out under SHS, water was driven across the furnace by a peristaltic pump at a controlled flow rate.

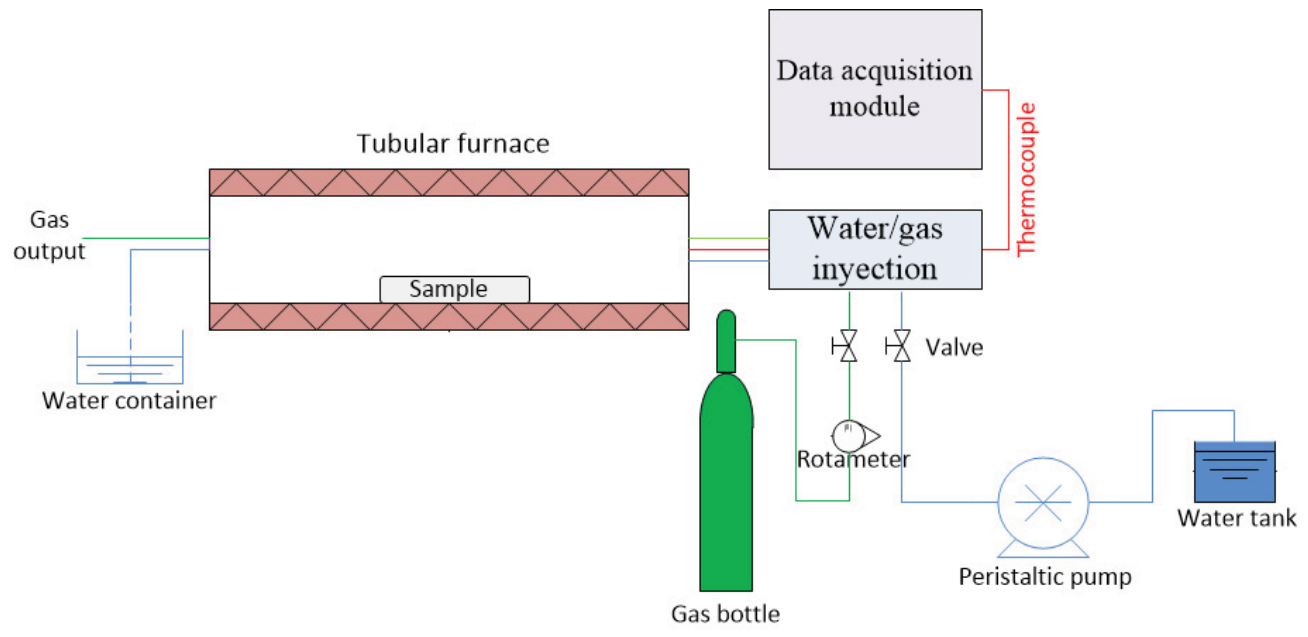

Fig.2. Thermal pretreatment furnace setup.

In each experiment, $\sim 150 \mathrm{mg}$ of the sample was weighed and placed in the middle of the furnace. Then, the gas/water injection system was connected and the sample heated to the minimum temperature required for attaining full decomposition under SHS or other gas selected. Thus, the samples were precalcined for 1 hour at $960^{\circ} \mathrm{C}$ under $\mathrm{CO}_{2}, 760^{\circ} \mathrm{C}$ under $\mathrm{N}_{2}$ and $725^{\circ} \mathrm{C}$ under $\mathrm{He}$. Gas flow rates of $100 \mathrm{~cm}^{3} / \mathrm{min}$ were employed in all cases. After calcination, the gas was switched to $\mathrm{N}_{2}\left(100 \mathrm{~cm}^{3} / \mathrm{min}\right)$ to avoid $\mathrm{CaO}$ hydroxylation and the temperature was decreased to room temperature. When SHS was used for precalcination, the sample was preheated under a gas flow rate of $100 \mathrm{~cm}^{3} / \mathrm{min}$ of $\mathrm{N}_{2}$ up to $\sim 600^{\circ} \mathrm{C}$ and the temperature was kept constant for $30 \mathrm{~min}$ before introducing water into the chamber. This procedure was intended to minimize condensation inside the furnace since the goal was to carry out the thermal pretreatment under SHS. The water flow rate, controlled by the peristaltic pump, was $2 \mathrm{~cm}^{3} / \mathrm{min}$. Full 
decomposition of the sample was obtained at $650^{\circ} \mathrm{C}$ for $1 \mathrm{~h}$ under SHS. Then, a gas flow rate of $\mathrm{N}_{2}$ of $100 \mathrm{~cm}^{3} / \mathrm{min}$ was introduced in the chamber and the temperature decreased to room temperature.

Calcination/carbonation experiments were performed using a thermogravimetric analyzer (TGA) Q5000IR from TA Instruments. The instrument consists of a high sensitive balance $(<0.1 \mathrm{mg})$ and a furnace heated by four IR halogen lamps that allow fast heating at controlled rates $\left(300^{\circ} \mathrm{C} / \mathrm{min}\right)$ and stable isotherms. Each test consisted of 20 carbonation/calcination cycles at $\mathrm{CaL}$ conditions that maximize the efficiency of CSP storage, namely calcination at low temperature under $\mathrm{He}$ and carbonation under $\mathrm{CO}_{2}$ at high concentration and high temperature with rapid transitions between the stages. ${ }^{15}$ Quick switch between $\mathrm{He}$ for calcination and $\mathrm{CO}_{2}$ for carbonation was achieved by using a gas flow rate of $200 \mathrm{~cm}^{3} / \mathrm{min}$. Each run was started with a precalcination stage at $725^{\circ} \mathrm{C}$ during $5 \mathrm{~min}$ by quickly heating the sample from room temperature at a heating rate of $300^{\circ} \mathrm{C} / \mathrm{min}$ under a pure $\mathrm{He}$ gas flow of $200 \mathrm{~cm}^{3} / \mathrm{min}$. After precalcination the temperature was quickly increased $\left(300^{\circ} \mathrm{C} / \mathrm{min}\right)$ to $850^{\circ} \mathrm{C}$ and the gas switched to pure $\mathrm{CO}_{2}$ with a gas flow of $200 \mathrm{~cm}^{3} / \mathrm{min}$ for carbonation, which was maintained during 5 minutes. Once the carbonation stage was ended, the temperature was quickly decreased to $150^{\circ} \mathrm{C}$, the gas was switched to pure $\mathrm{He}$ and the temperature maintained for 2 minutes. Then, the sample was calcined again by increasing the temperature $\left(300^{\circ} \mathrm{C} / \mathrm{min}\right)$ to $725^{\circ} \mathrm{C}$ maintaining the $\mathrm{He}$ atmosphere. The temperature was then decreased again at $300^{\circ} \mathrm{C} / \mathrm{min}$ to $150^{\circ} \mathrm{C}$ and maintained for 2 minutes under He, after which a new carbonation stage was started. The intermediate steps at $150^{\circ} \mathrm{C}$ were introduced in order to mimic the extraction of sensible heat from the solids exiting the carbonator and calciner before storage, as proposed in the CaLCSP integration scheme, ${ }^{15}$ leading to a rapid cooling of the solids. The sample is placed inside a SiC enclosure heated by the IR halogen lamps, which minimizes undesired heat transfer phenomena. Samples of small and fixed mass $(10 \mathrm{mg})$ were used to ensure an optimum heat and mass transfer during the gas- solid reactions occurring throughout the experiments. ${ }^{29}$ TGA results reproducibility was checked in our work by performing runs at same conditions on different samples.

The samples were analyzed by X-ray diffraction (XRD) by means of a Miniflex 600 Rigaku operating at $40 \mathrm{kV}$ and $15 \mathrm{~mA}$ and using radiation $\mathrm{CuK} \alpha$. Particle size distribution (PSD) was measured using a Mastersizer 3000. To this end, the samples 
were dispersed in isopropanol and sonicated for a few seconds to facilitate particles dispersion. Specific surface and pore size distribution were studied by means of $\mathrm{N}_{2}$ physisorption (ASAP2010 from Micromeritics). The microstructure of the samples was analyzed by scanning electron microscopy (SEM) employing a HITACHI S5200 SEM microscope.

\section{Results and discussion}

Thermal pretreatments of limestone A samples were driven on diverse atmospheres and under different temperatures to achieve full calcination for $1 \mathrm{~h}$ in all the cases as specified in Table 2. Furthermore, dry nano-silica powder was physically mixed with a sample of limestone A (15\% nanosilica / 85\% limestone wt/wt) after which the mixture was calcined in SHS. Hydrophilic nano-silica provided by Evonik (Aerosil ${ }^{3} 300$ de Evonik Industries) was used to this end. Remarkably, full calcination under SHS was achieved under a relatively low temperature $\left(650^{\circ} \mathrm{C}\right)$ in agreement with previous studies, which has been attributed to a catalytic effect of $\mathrm{H}_{2} \mathrm{O}$ on decarbonation in previous works. $^{30}$ On the other hand, calcination under pure $\mathrm{CO}_{2}$ required a very high temperature $\left(960^{\circ} \mathrm{C}\right)$ as observed also elsewhere. ${ }^{31}$

Table 2. Calcination atmosphere and temperatures employed for thermal pretreatment (SHS: Super-heated steam).

\begin{tabular}{|c|c|c|c|c|c|}
\hline Gas & SHS & $\begin{array}{c}\text { SHS with } \\
\text { nanosilica } \\
(15 \% \text { wt })\end{array}$ & He & $\mathbf{N}_{2}$ & OO $_{2}$ \\
\hline T ( $\left.{ }^{\circ} \mathrm{C}\right)$ & 650 & 650 & 725 & 760 & 960 \\
\hline
\end{tabular}


The thermally pretreated samples were analyzed by X-ray diffraction (Fig. 3). When calcination was carried out under SHS, $\mathrm{Ca}(\mathrm{OH})_{2}$ Bragg reflection peaks were observed (Fig.3d-e) possibly caused by water condensation in the tubular furnace due to temperature gradients, which may lead to partial hydroxylation. As expected, the XRD diffractograms show qualitatively a higher degree of crystallinity (narrower reflection peaks were obtained) for the sample pretreated under $\mathrm{CO}_{2}$ (Fig. 3a) at high temperature, which favors solid-state diffusion during calcination thus leading to an enlargement of the $\mathrm{CaO}$ crystallite size. ${ }^{32}$

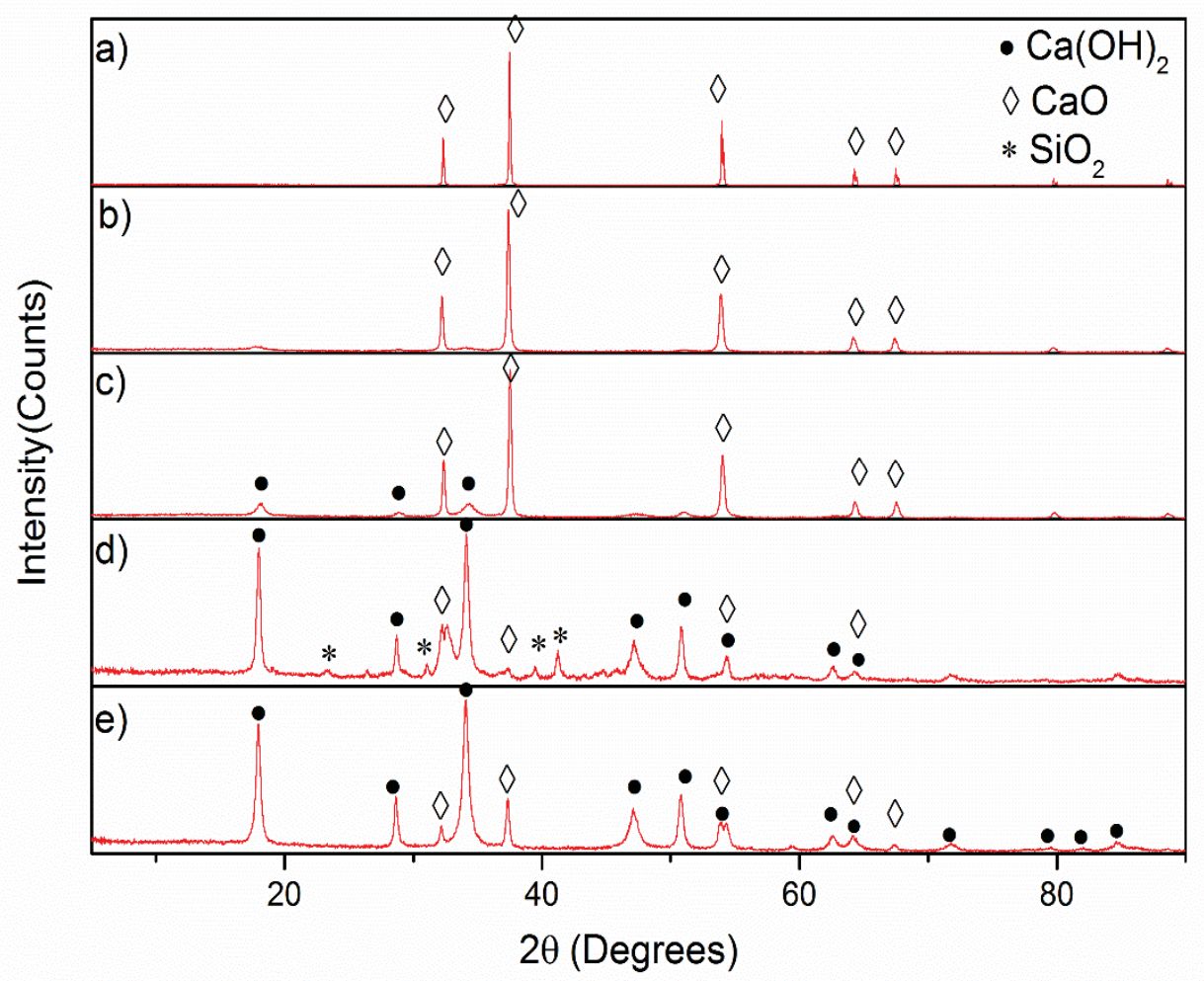

Fig. 3. X-Ray diffractograms of limestone A samples thermally pretreated for $1 \mathrm{~h}$ under a) $\mathrm{CO}_{2}$ at $960^{\circ} \mathrm{C}$, b) $\mathrm{N}_{2}$ at $760^{\circ} \mathrm{C}, \mathrm{c}$ ) $\mathrm{He}$ at $725^{\circ} \mathrm{C}, \mathrm{d}$ ) SHS at $650^{\circ} \mathrm{C}$ (mixed with nano-silica) and e) SHS at $650^{\circ} \mathrm{C}$.

To analyse the $\mathrm{CaO}$ multicycle activity behaviour under CaL-CSP conditions, $\mathrm{CaO}$ conversion in the Nth carbonation stage $\left(X_{N}\right)$ was obtained from the thermograms (an example is shown in Fig.4) using equation (2), where $W_{\text {carb }}$ is the mass of the sample at the end of the carbonation stage, $W_{i n i}$ is the mass of the sample just before carbonation and $M_{\mathrm{CaO}}$ and $\mathrm{MCO}_{\mathrm{CO}}$ are the molecular weights of $\mathrm{CaO}$ and $\mathrm{CO}_{2}$ respectively. 


$$
X=\frac{\left(W_{c a r b}-W_{i n i}\right)}{W_{i n i}} \frac{M_{C a O}}{M_{\mathrm{CO}_{2}}}
$$
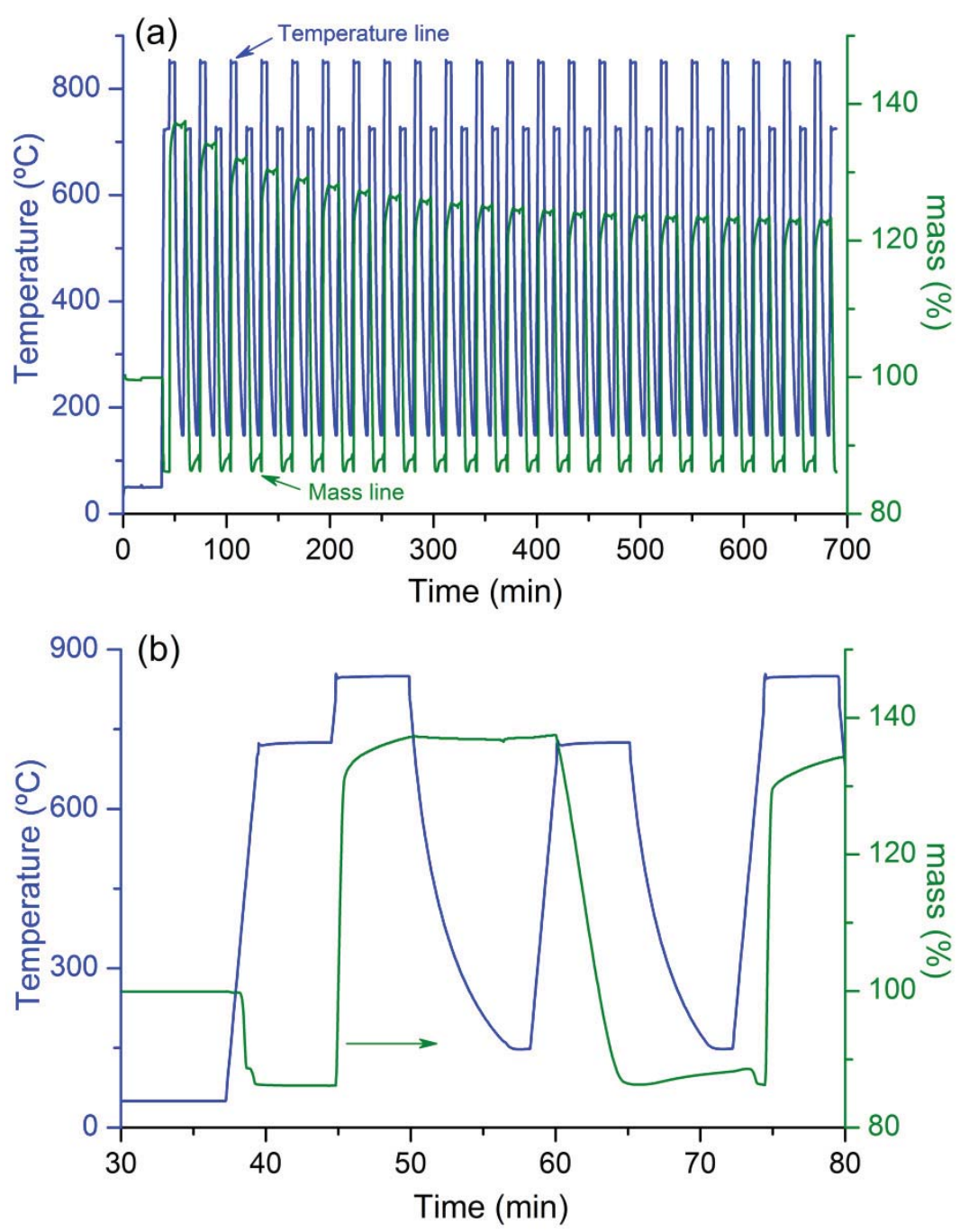

Fig. 4. (a) Time evolution of temperature and sample mass \% along 20 carbonation/calcination cycles at $\mathrm{CaL}-\mathrm{CSP}$ storage conditions for $\mathrm{CaO}$ resulting from limestone A pretreatment at $760^{\circ} \mathrm{C}$ in $\mathrm{N}_{2}$. The 1st cycle is detailed in (b). The slight drop in the weight baseline below $100 \%$ is due to partial carbonation and hydroxylation of the $\mathrm{CaO}$ sample that results from pretreatment which occurred between the end of the pretreatment and the start of the TGA test.

$\mathrm{CaO}$ multicycle conversion data are plotted in Fig.5 for all the pretreated samples over 20 carbonation/calcination cycles carried out under CaL-CSP storage conditions, and compared with the $\mathrm{CaO}$ multicycle conversion of the raw limestones $\mathrm{A}$ and $\mathrm{B}$. For the sake of comparison, multicycle $\mathrm{CaO}$ conversion results obtained for 
limestone $\mathrm{A}$ at $\mathrm{CaL}$ conditions for $\mathrm{CO}_{2}$ capture reported elsewhere are also plotted in Fig. 5 (see ref. [22] for further details). As may be seen, the type of $\mathrm{CaL}$ conditions (either for CSP energy storage or $\mathrm{CO}_{2}$ capture) determines fundamentally the multicycle performance of limestone derived $\mathrm{CaO}$. Thus, the harsh calcinations employed at $\mathrm{CaL}$ conditions for $\mathrm{CO}_{2}$ capture lead to a severe drop of $\mathrm{CaO}$ conversion after just a few cycles as widely reported in the recent literature. ${ }^{22}$ On the other hand, $\mathrm{CaO}$ derived from raw limestone exhibits a relatively much higher multicycle activity at $\mathrm{CaL}$ conditions for CSP energy storage arguably due not just to the mild calcination conditions employed (relatively low temperature in absence of $\mathrm{CO}_{2}$ ) but also because of the high temperature/high $\mathrm{CO}_{2}$ concentration used for carbonation, which enhances significantly the carbonation reaction.

Let us now focus on the effect of pretreatment on the multicycle $\mathrm{CaO}$ conversion performance under CaL conditions for CSP energy storage. As seen in Fig. 5, thermal pretreatment under $\mathrm{He}, \mathrm{N}_{2}$ and SHS lead to similar performances as compared to the raw sample. On the other hand, the sample precalcined under $\mathrm{CO}_{2}$ at high temperature presents initially a substantially lower activity presumably due to a drastic reduction of the $\mathrm{CaO}$ reactive surface area by enhanced sintering during pretreatment. Despite of the low initial activity caused by this pretreatment, a notable reactivation is observed along on the following cycles. Arguably, the low calcination temperature used in the cycles allows a progressive regeneration of $\mathrm{CaO}$ surface area resulting from decarbonation of the $\mathrm{CaCO}_{3}$ formed after each cycle. The stable activity of the $\mathrm{CaO}$ resulting from the limestone pretreated under $\mathrm{CO}_{2}$ at high temperature could be explained from the presence of macropores formed during thermal pretreatment that remain stable along the multiple CaL cycles. Macropore stability has been identified in the recent work by Xu et al. ${ }^{33}$ as a key factor on improving the multicycle performance of $\mathrm{CaO}$ based sorbents in the $\mathrm{CaL}$ process. Previous works have also shown that the multicycle $\mathrm{CaO}$ stability is enhanced for thermally pretreated samples under high temperature. ${ }^{34}$

A relevant observation that can be made from Fig. 5 is that the limestone sample pretreated under SHS and mixed with nanosilica exhibits a rather low multicycle activity. As shown in Fig. 5 the initial $\mathrm{CaO}$ conversion for the nanosilica/CaO composite obtained in our work under CaL conditions for CSP energy storage is rather low and deactivation along successive cycles is not hindered. This poor performance contrasts with the observation reported in previous works on the use of nanosilica, ${ }^{26}$ 
which enhances the performance of the material at $\mathrm{CaL}$ conditions for $\mathrm{CO}_{2}$ capture by mitigating the loss of $\mathrm{CaO}$ surface area due to sintering.

Regarding the multicycle behaviour exhibited by the different batches of raw limestone, Fig. 5 shows that sample B suffers a slightly more marked deactivation than sample A, which could be explained in principle by the concentration of impurities present in both samples having an effect on $\mathrm{CaO}$ sintering. However, the expected degree of $\mathrm{CaO}$ sintering is not significant at the mild $\mathrm{CaL}$ calcination conditions for CSP energy storage used in our tests and the concentration of impurities is quite small. As will be seen ahead, at these CaL conditions, the diverse mean particle size of the samples could play a relevant role through pore plugging.

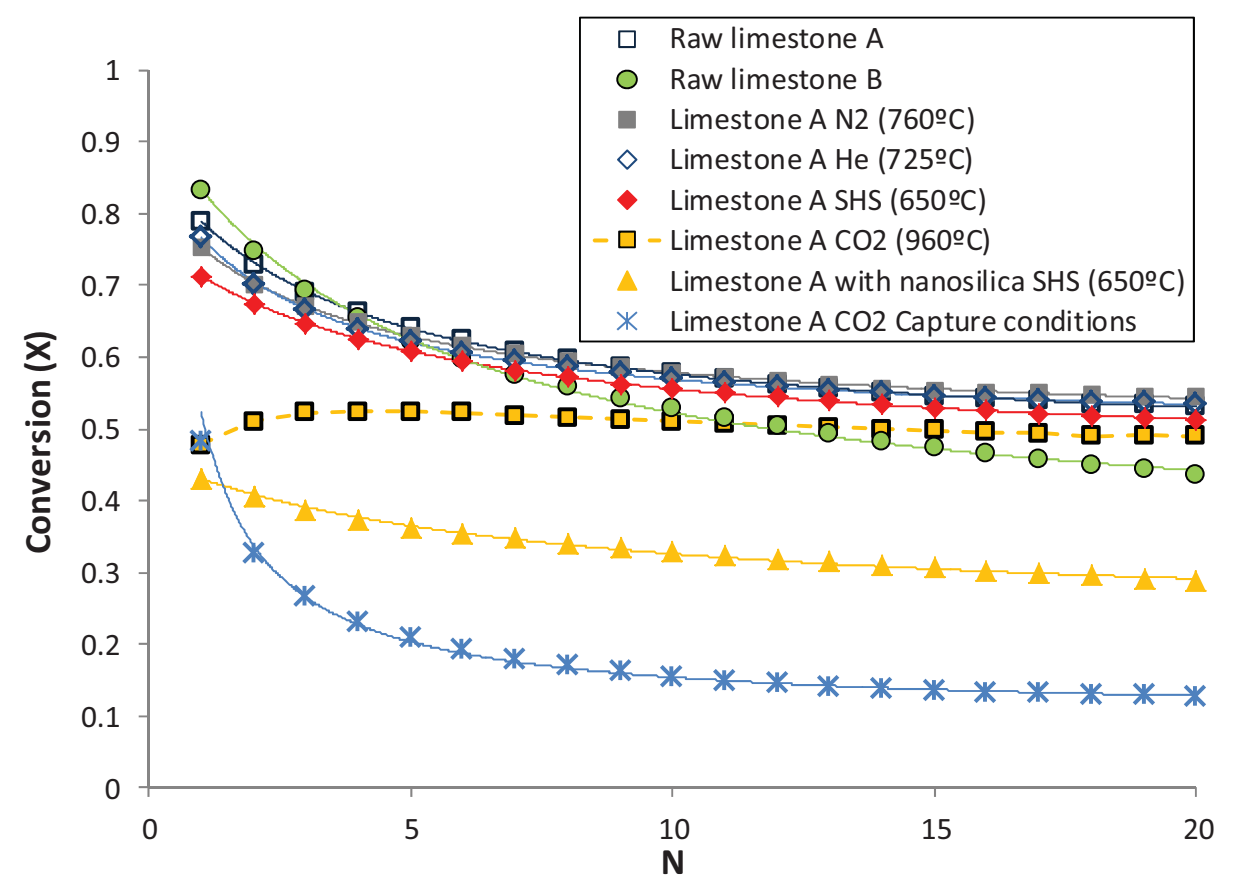

Fig. 5. $\mathrm{CaO}$ conversion of the sorbents derived from natural limestone (batches $\mathrm{A}$ and $\mathrm{B}$ ) and pretreated samples of limestone A under different atmospheres (indicated in the inset) at $\mathrm{CaL}$ conditions for CSP energy storage. $\mathrm{CaO}$ conversion data obtained for limestone A cycled at $\mathrm{CaL}$ conditions for $\mathrm{CO}_{2}$ capture are shown for comparison. ${ }^{22}$ Solid lines are best fit curves of Eq. 3 to experimental data.

Multicycle $\mathrm{CaO}$ conversion data can be generally well fitted by the semi-empirical equation $(3):^{31,35}$ 


$$
X_{N}=X_{r}+\frac{X_{1}}{k(N-1)+\left(1-\frac{X_{r}}{X_{1}}\right)^{-1}} ; \quad(N=1,2, . .)
$$

Here $X_{l}$ is $\mathrm{CaO}$ conversion at the 1 st cycle, $N$ is the cycle number, $k$ is the deactivation rate constant and $X_{r}$ is the residual conversion towards which $\mathrm{CaO}$ conversion converges after a large number of cycles. Residual conversion values obtained from the best fits to conversion data are shown in Table 3, except for the sample pretreated under $\mathrm{CO}_{2}$ whose behaviour does not conform to Eq. 3 and after 20 cycles shows a stable conversion close to 0.5. As seen in Fig. 5, Eq. 3, widely employed in the literature as fitting equation of multicycle $\mathrm{CaO}$ conversion data, provides a quite well fit to our experimental data $\left(\mathrm{R}^{2}>0.99\right)$, which allows us to reliably derive a value of the residual $\mathrm{CaO}$ conversion. Thus, the residual conversions derived for the limestone samples pretreated under different conditions (Table 3) are quite similar and close to 0.5 regardless of the gas and temperature used in these pretreatments. Thus, it may be concluded that thermal pretreatment determines the performance of the sample along the first cycles but the memory of this treatment is lost after a few cycles. On the other hand, an important effect is observed when nanosilica is added to the sample, which reduces considerably the residual conversion as opposed to the effect observed at $\mathrm{CaL}$ conditions for $\mathrm{CO}_{2}$ capture. ${ }^{25}$ Likewise, it is seen that the raw limestone samples from different batches show significantly different values of the residual conversions.

Table 3. Residual conversion of $\mathrm{CaO}$ from raw samples of limestone $\mathrm{A}$ and $\mathrm{B}$ and samples of limestone A pretreated under different atmospheres and temperatures and mixed with nanosilica.

\begin{tabular}{|c|c|c|c|c|c|c|c|}
\hline Sample & \multicolumn{5}{|c|}{ Limestone A } & Limestone B \\
\cline { 2 - 7 } & Raw & SHS & $\begin{array}{c}\text { SHS+nano- } \\
\text { SiO }\end{array}$ & He & $\mathbf{N}_{2}$ & $\mathbf{C O}_{2}$ & Raw \\
\hline $\mathbf{X}_{\mathbf{r}}$ & 0.475 & 0.449 & 0.232 & 0.490 & 0.495 & 0.488 & 0.323 \\
\hline
\end{tabular}




\section{SEM analysis}

All the thermally pretreated and raw samples were analysed by SEM in order to seek for a link between the surface morphology of the particles and multicycle $\mathrm{CaO}$ conversion data measured.
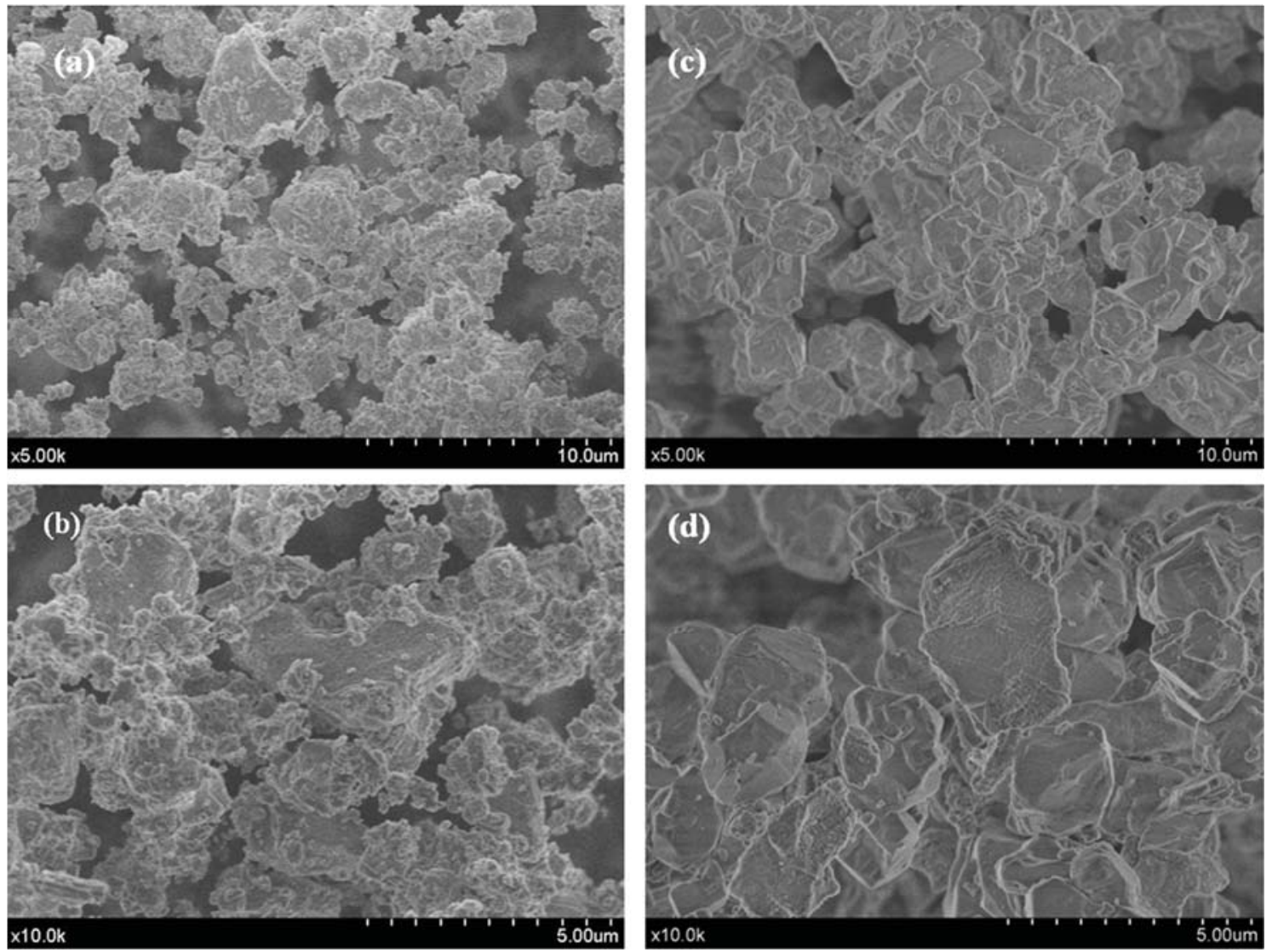

Fig. 6. SEM micrographs of raw samples of limestone A ( $a \mathrm{y} b$ ) and B (c y d).

Figure 6 shows micrographs of raw limestone samples A and B at different magnifications. As may be seen, the main difference inferred from these pictures is that sample A has a significant higher fraction of smaller micron-size particles as compared to sample B. 

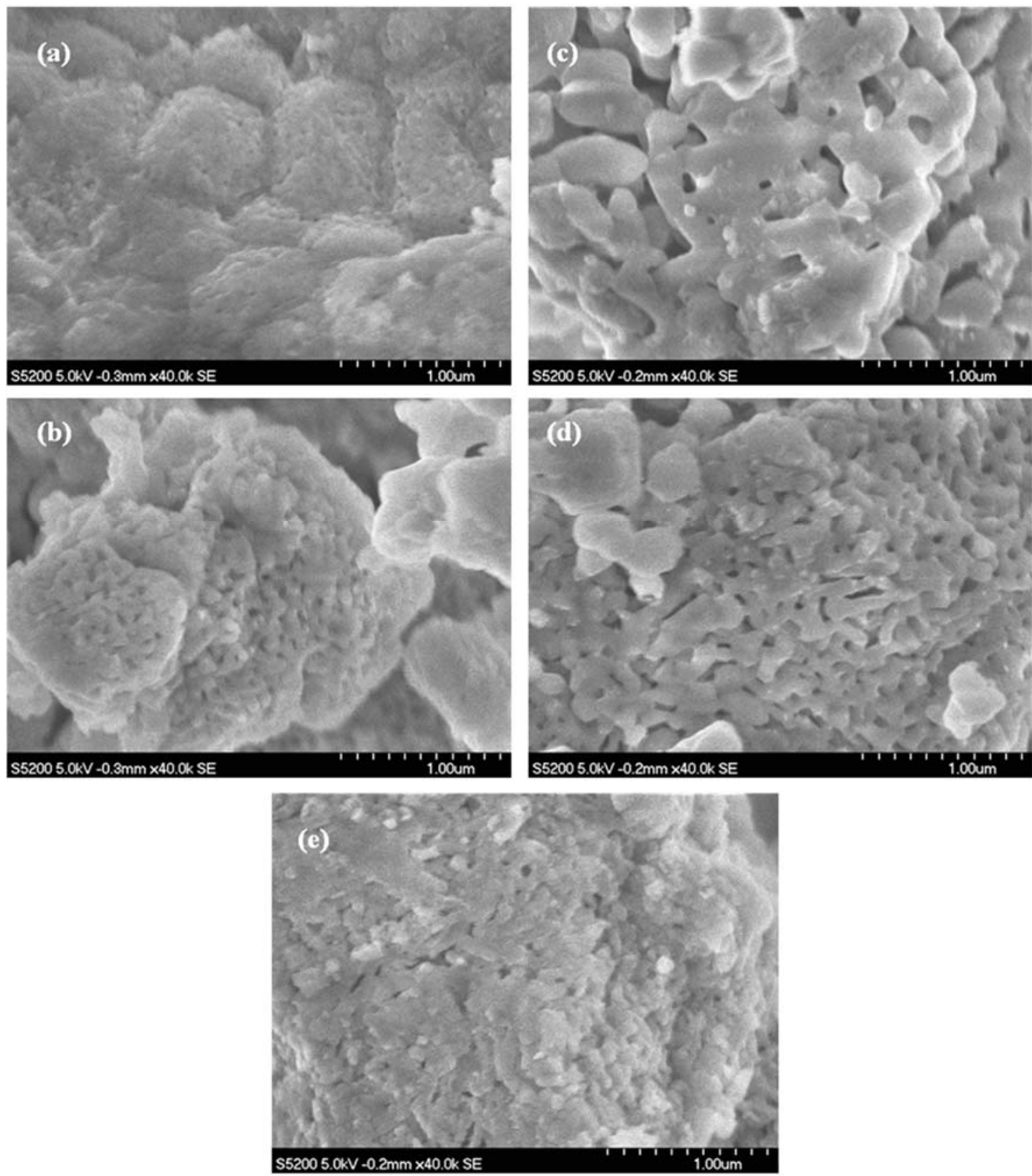

Fig. 7. SEM micrographs of limestone A pretreated samples in a) SHS (with nano-silica added), b) $\left.\mathrm{He}, \mathrm{c}) \mathrm{CO}_{2}, \mathrm{~d}\right) \mathrm{N}_{2}$ and e) SHS.

SEM micrographs of pretreated limestone A samples are shown in Fig.7. These photographs give an idea on the porosity of the $\mathrm{CaO}$ skeleton that results from the thermal pretreatment. As can be seen, the different pretreatments carried out lead to significant differences in the $\mathrm{CaO}$ microstructure. Thus, the sample calcined under $\mathrm{CO}_{2}$ at high temperature (Fig. 7c) presents a notably larger pore size and a marked sintering 
of the $\mathrm{CaO}$ grains as would be expected from previous works. ${ }^{36}$ On the opposite side, precalcination under SHS at relatively low temperature of the sample with added nanosilica yields significantly less sintering (Fig.7a) as could be anticipated from results reported in previous works showing a marked $\mathrm{CaO}$ sintering hindrance effect of nanosilica when used as additive. ${ }^{25}$ In principle, this effect would lead to a large $\mathrm{CaO}$ surface area available for fast carbonation in apparent contrast with the detrimental effect of nanosilica addition on the multicycle $\mathrm{CaO}$ conversion obtained at $\mathrm{CaL}$ conditions for CSP energy storage (Fig. 5). This observation suggests that promoted sintering is not the main physical mechanism that determines $\mathrm{CaO}$ activity along carbonation/calcination cycles at CaL conditions for CSP storage.

\section{Particle size distribution (PSD) analysis}

Figure 8 illustrates the PSDs measured for the different samples analysed in our work after thermal pretreatment and before being subjected to the $\mathrm{CaL}$ cycles. Remarkably, the results suggest an inverse correlation between particle size and the residual $\mathrm{CaO}$ conversion of the samples. Fig. 9 shows data on the mean particle size obtained from the PSDs (D50) versus residual $\mathrm{CaO}$ conversion $\left(\mathrm{X}_{\mathrm{r}}\right)$ values derived from the TGA tests. This correlation might be arguably caused by a physical phenomenon that would limit carbonation at the CaL conditions of our tests specific for CSP energy storage, namely pore plugging. At these conditions, carbonation at high temperature and high $\mathrm{CO}_{2}$ pressure occurs very fast as seen in the thermogram shown in Fig. 4b. Moreover, the carbonate layer formed on the $\mathrm{CaO}$ surface during the fast reactioncontrolled stage would reach a thickness over $100 \mathrm{~nm}$ at these high temperature and high $\mathrm{CO}_{2}$ concentration. ${ }^{37}$ On the other hand, calcination at the relatively low temperature for $\mathrm{CaO}$ regeneration would not lead to marked sintering thus yielding small pores (as will be seen below from the physisorption analysis). CaL conditions for CSP storage would thus favour the plugging of the small pores at the external surface of the particles, which would hamper the access of $\mathrm{CO}_{2}$ to the interior of the $\mathrm{CaO}$ particles. As particle size is increased, pore plugging would thus impede carbonation on a relatively larger $\mathrm{CaO}$ surface area thus having a deeper negative impact on $\mathrm{CaO}$ conversion in the fast reaction controlled stage. 

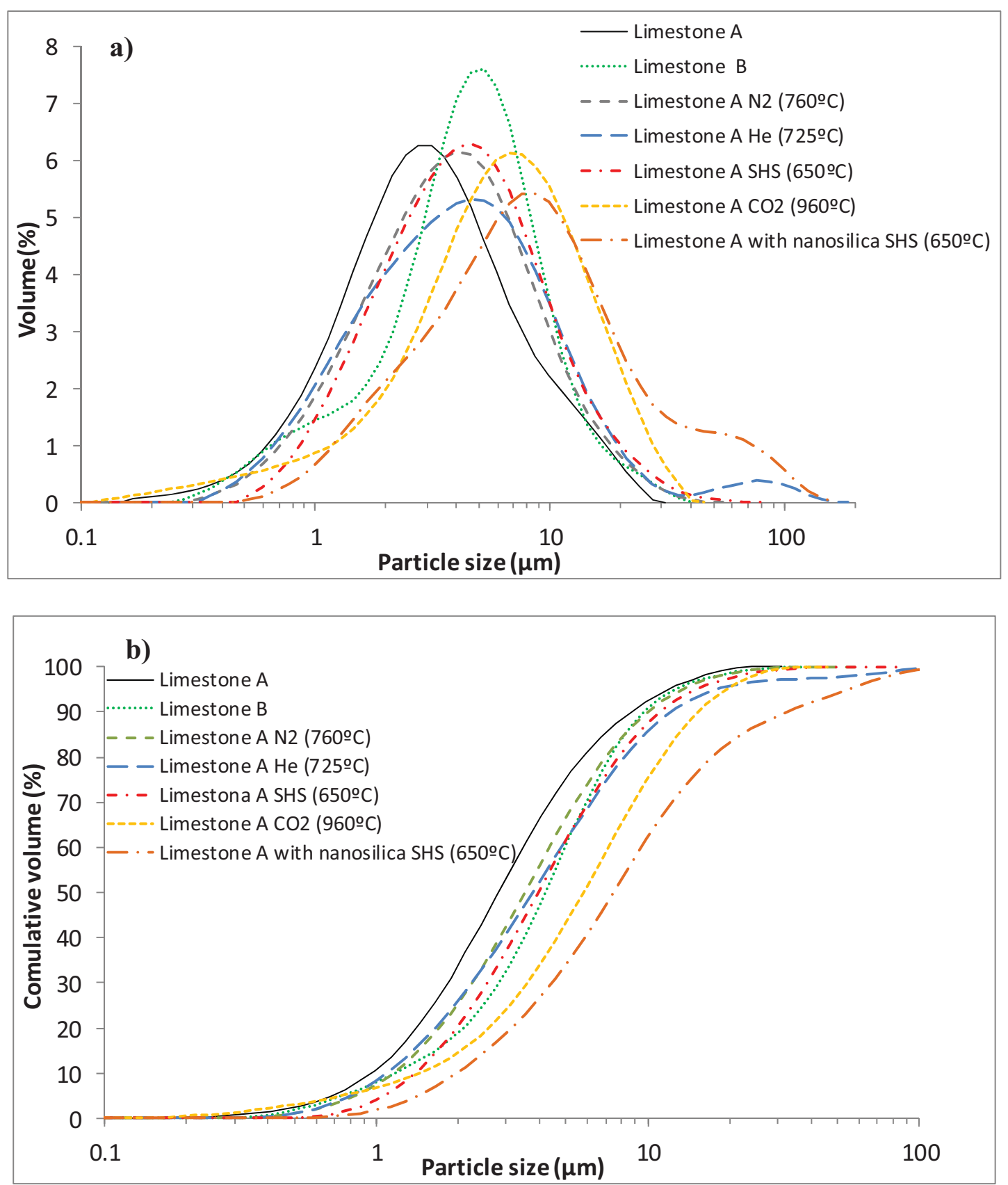

Fig. 8. a) Volume particle size distribution of $\mathrm{CaO}$ derived from raw and pretreated limestone $\mathrm{A}$ samples under different atmospheres and temperatures and from raw limestone B. b) Cumulative particle size distribution 


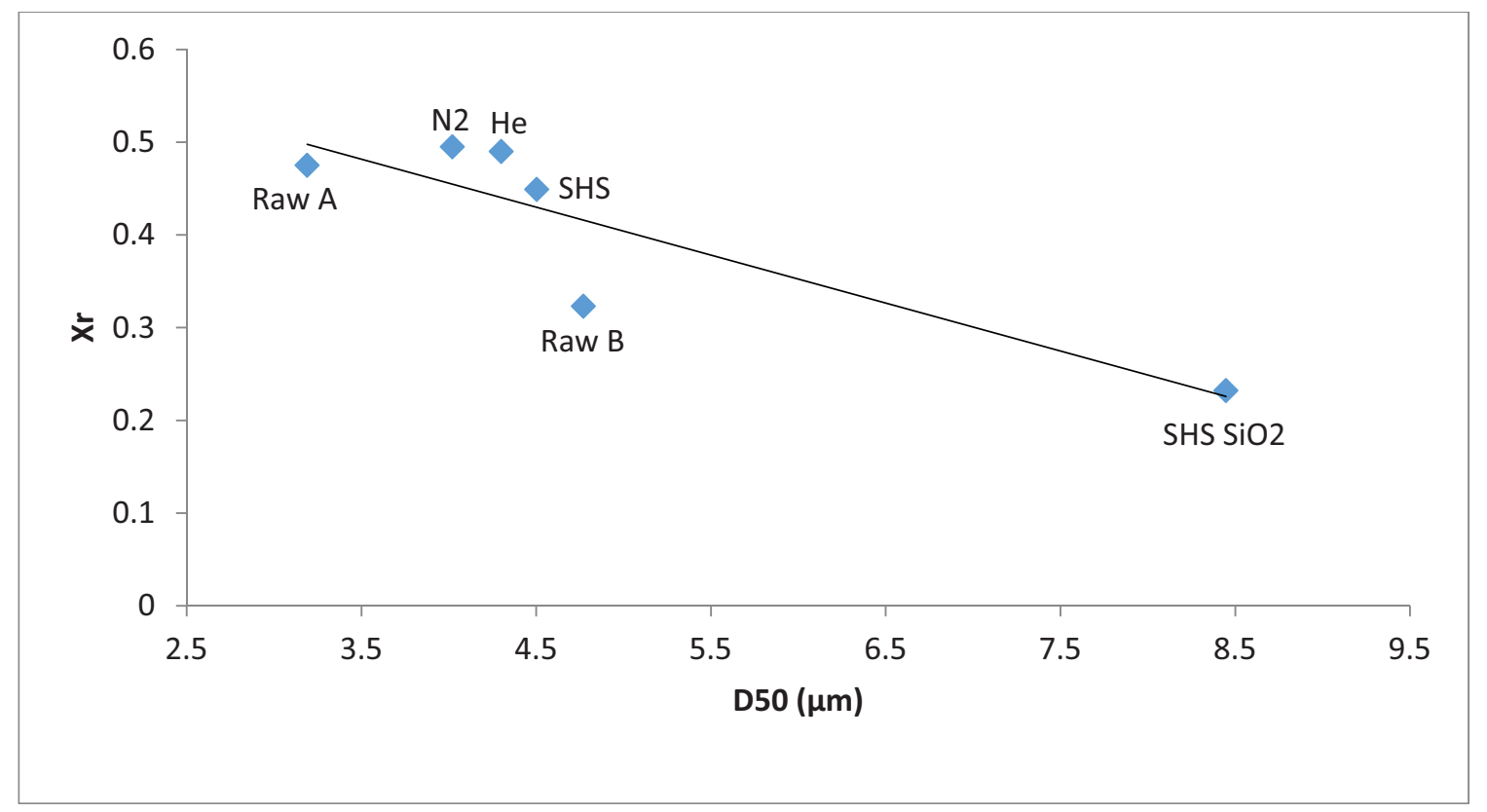

Fig. 9. Correlation between mean particle diameter (D50) and residual $\mathrm{CaO}$ conversion (Xr). The labels indicate the type of sample and for limestone A the gas under which thermal pretreatment was performed.

\section{Physisorption analysis}

Values obtained for the BET surface area of the pretreated samples are shown in Table 4. As would be expected, the addition of nanosilica leads to a significant increase of the surface area partly due to its nano-sized porous structure. Besides, nanosilica contributes to a reduction of $\mathrm{CaO}$ pore size in the mesoporous range as can be seen in the pore size distribution (Fig. 10).

Table 4. BET surface of limestone A samples pretreated under different atmospheres

\begin{tabular}{|l|c|c|c|c|c|c|}
\hline \multicolumn{1}{|c|}{ Gas } & SHS & $\begin{array}{c}\text { SHS with } \\
\text { nanosilica } \\
(15 \% \text { wt })\end{array}$ & He & $\mathrm{N}_{2}$ & $\mathrm{CO}_{2}$ & $\begin{array}{c}\text { Limestone } \\
\text { A (1 }\end{array}$ \\
\hline $\begin{array}{l}\text { st } \\
\text { BET } \\
\text { surface } \\
\text { area }\left(\mathrm{m}^{2} / \mathrm{g}\right)\end{array}$ & 13 & 20 & 14 & 13 & 8 & 13 \\
\hline
\end{tabular}


Pore size distributions calculated by the BJH method are plotted in Fig.10. As can be seen, the thermally pretreated samples under $\mathrm{N}_{2}$, He and SHS have a similar pore distribution with a main peak around $30-40 \mathrm{~nm}$, which is consistent with the average size of the pores observed in the SEM micrographs (Fig.7). The similar particle size and pore size of these samples would explain why they show a similar multicycle $\mathrm{CaO}$ conversion behaviour as seen in Fig.5 if pore plugging were the driving factor that limits carbonation at the $\mathrm{CaL}$ conditions used. Even though the precalcination temperatures are diverse under these atmospheres, taking into account the small size of these pores and the carbonation conditions (high temperature and high $\mathrm{CO}_{2}$ concentration), pore plugging would similarly limit carbonation for the $\mathrm{CaO}$ that stems from calcination under such diverse atmospheres. On the other hand, a noticeable effect of nanosilica is the shift of the mesoporous $\mathrm{CaO}$ pore size distribution to smaller pore sizes as was anticipated from our SEM analysis and previous works. ${ }^{25}$ Since plugging of pores during carbonation becomes more likely as the size of the pores is decreased, $\mathrm{CaO}$ conversion would be further hampered as observed in our TGA tests (Fig 5). It must be also taken into account that the mean particle size of this sample is slightly larger than for the other samples (Fig.8), which would enhance further the detrimental effect of pore plugging.

The typical size of the carbonate layer that is quickly produced during the fast carbonation stage at CaL conditions for CSP energy storage (above $100 \mathrm{~nm}$ ) ${ }^{37}$ is larger than the mean pore size obtained from the pore size distributions, which reinforces the role of pore plugging on the multicycle $\mathrm{CaO}$ activity at these conditions. On the other hand, for the sample precalcined under $\mathrm{CO}_{2}$, the SEM analysis (Fig. 7c) shows external pores of size over $100 \mathrm{~nm}$. Although the size of macropores is out of range for $\mathrm{N}_{2}$ physisorption analysis, previous analysis based on mercury intrusion porosimetry ${ }^{38}$ have shown that calcination of limestone under $\mathrm{CO}_{2}$ at high temperature $\left(960^{\circ} \mathrm{C}\right)$, which correspond to the same conditions of pretreatment in our test, shifts the $\mathrm{CaO}$ pore size distribution to sizes above $100 \mathrm{~nm}$ (peaking at $189 \mathrm{~nm}$ ). In this case, there would be little surface area available at the first cycle for carbonation but pore plugging would not be relevant in limiting the reaction, which together with the stability of macropores generated by thermal pretreatment, ${ }^{33-34}$ would allow for a stable multicycle $\mathrm{CaO}$ conversion as seen in Fig. 5. 


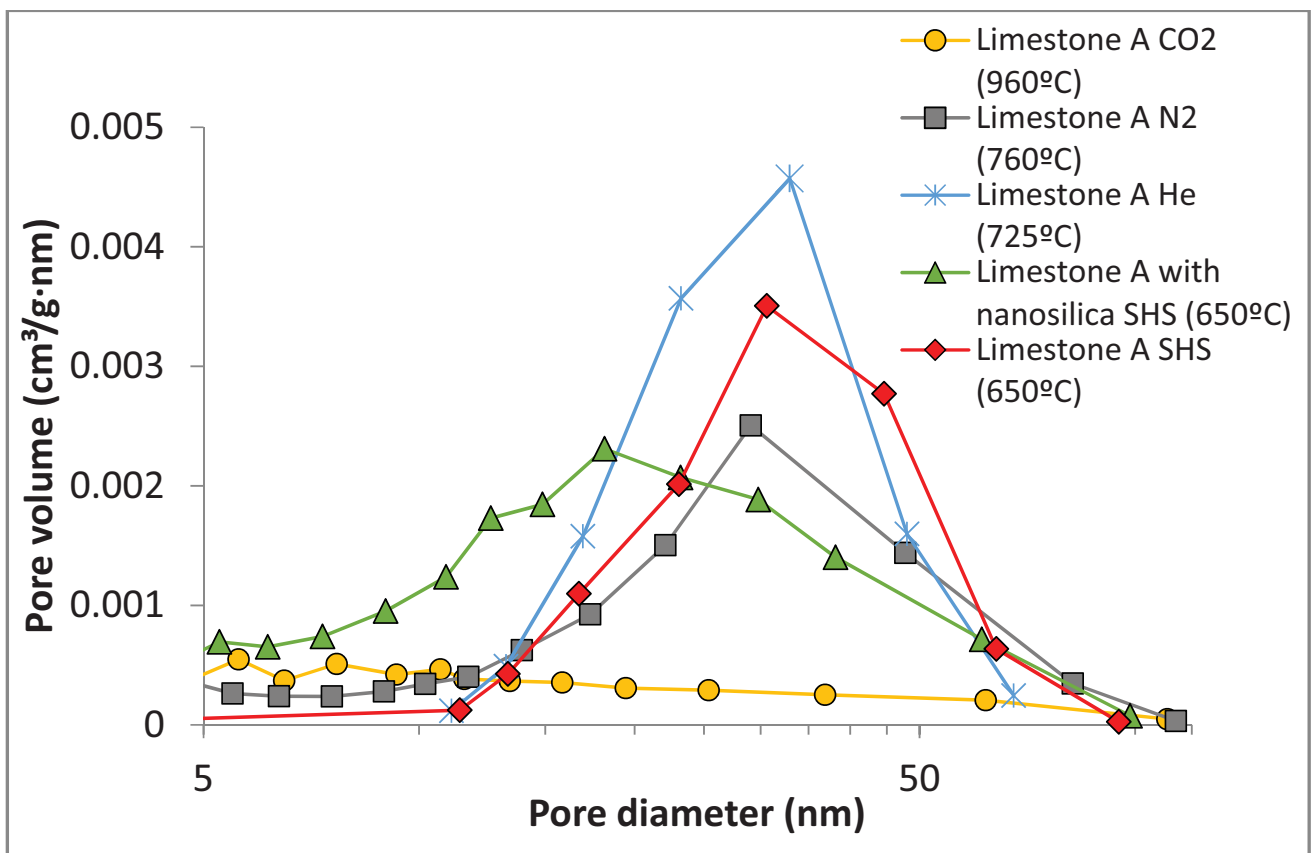

Fig. 10. Pore size distribution calculated by the BJH method for limestone A samples precalcined under different atmospheres as indicated.

The SEM picture in Fig. 11 shows the surface of a particle from the limestone A sample precalcined under $\mathrm{N}_{2}$ and cycled at CaL conditions for CSP energy storage (ending in calcination) which further supports the argument on the important limitation posed by pore plugging on the $\mathrm{CaO}$ multicycle activity at these conditions. As may be seen, a part of the particle's surface has been broken during manipulation, which has left exposed a relatively porous $\mathrm{CaO}$ skeleton inside the particle whereas the rest of the surface is covered by a sintered $\mathrm{CaO}$ layer. Thus, only a relatively small fraction of the material at the particle's surface would be active along the carbonation/calcination cycles while the relatively porous $\mathrm{CaO}$ skeleton remains inaccessible to the $\mathrm{CO}_{2}$. Pore plugging would be therefore a main limiting factor on carbonation in the fast reaction controlled regime, leading to a significant decay of the sorbent activity in short residence times with the number of cycles, which is further enhanced the larger the particle is. 

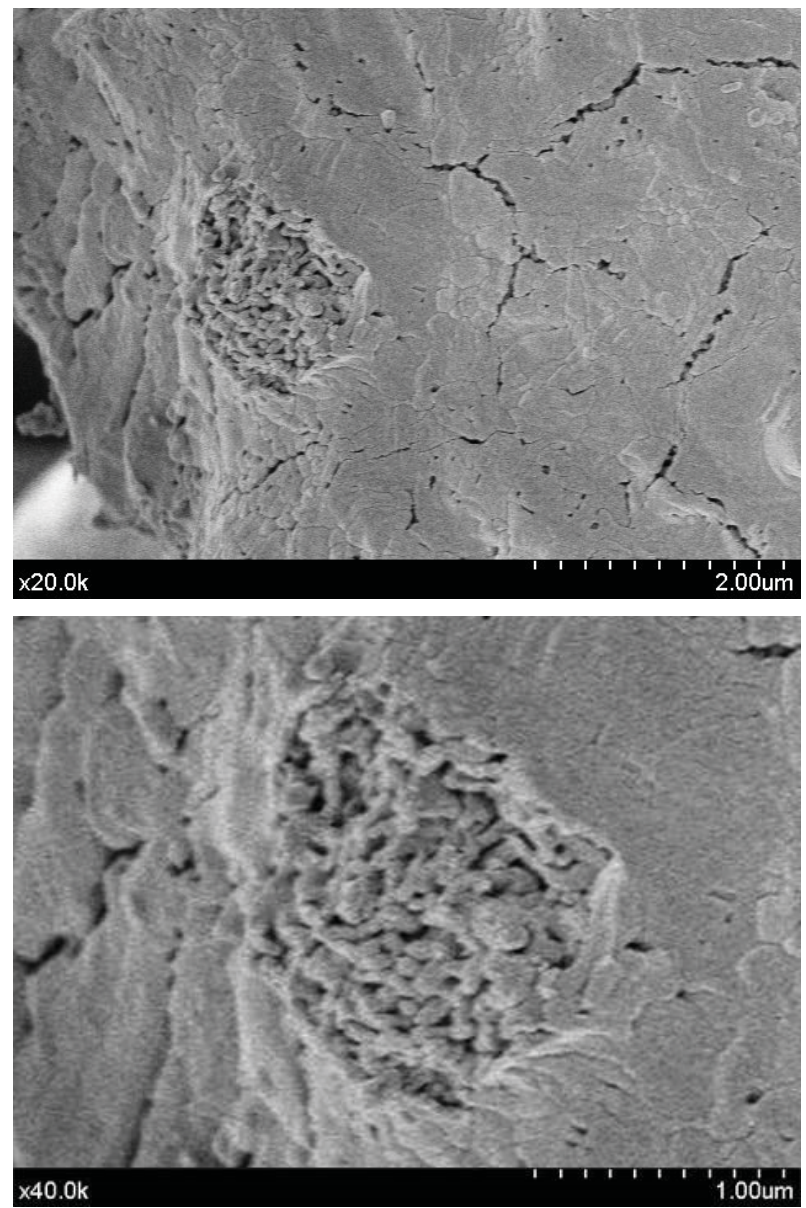

Fig. 11. SEM pictures of a limestone sample precalcined under $\mathrm{N}_{2}$ after being subjected to $\mathrm{CaL}$ cycles at conditions for CSP energy storage (ending in calcination).

Further support to the argument on pore plugging as a main limiting factor on the multicycle $\mathrm{CaO}$ conversion performance of limestone at $\mathrm{CSP}-\mathrm{CaL}$ conditions can be found in the experimental results reported by $\mathrm{Lu}$ et al. ${ }^{39}$ who tested a number of $\mathrm{CaO}$ based sorbents at calcination conditions similar to those now judged as suitable for TCES in CSP plants involving a relatively low calcination temperature $\left(700^{\circ} \mathrm{C}\right)$ under He. Moreover, the $\mathrm{CO} 2 \mathrm{vol} \%$ in $\mathrm{Lu}$ et al. tests was also relatively high in the carbonation stage, which was carried out in a window of temperatures extending up to $800^{\circ} \mathrm{C}$. As inferred from the results obtained, Lu et al. argued that a main factor limiting the $\mathrm{CaO}$ carbonation performance in multiple carbonation/decarbonation cycles was the plugging of pores rather than sorbent sintering in agreement with our observations. Additionally, Lu et al. observed that the addition of nanosilica did impair the sorbent carbonation performance at these carbonation/calcination conditions as we have also 
seen in our work. It is also remarkable that the pore size distribution measured by Lu et al. after many cycles remained stable for a Ca-acetate based sorbent, which exhibited a stable conversion along the cycles.

The recent work by Pinheiro et al. ${ }^{40}$ also points towards pore plugging as a determinant mechanism on the multicycle $\mathrm{CaO}$ carbonation performance when the $\mathrm{CaO}$ skeleton exhibits narrow bottleneck pore mouths susceptible of being blocked by the $\mathrm{CaCO}_{3}$ product built upon the external surface of the particles. Thus, Pinheiro et al tested a number of $\mathrm{CaO}$ based sorbents and observed a poor performance for the samples with increased BET surface area and smaller pores, which is consistent with pore plugging as a relevant mechanism limiting carbonation in some cases. Interestingly, Pinheiro et al. observed this apparently anomalous behaviour by means of tests in a fixed bed reactor whereby calcination was carried out under $\mathrm{N}_{2}$ at a relatively moderate temperature $\left(800^{\circ} \mathrm{C}\right)$, which would not cause excessive sintering of the regenerated $\mathrm{CaO}$ structure.

Experiments in fluidization environments should be pursued in future works to gain further knowledge on the sorbents' behaviour under CaL-CSP storage conditions. In particular, it would be interesting to investigate whether the significant improvement on powder flowability provided by the addition of nanosilica (as reported in ref. [41]), which increases the gas-solid contacting efficiency, would help improving the $\mathrm{CaO}$ carbonation performance in fluidized beds at CaL-CSP conditions thus counteracting its detrimental effect by enhancing pore plugging.

\section{Conclusions}

In this work we have analysed the role of thermal pretreatment and modification with nanosilica on the multicycle conversion performance of limestone derived $\mathrm{CaO}$ at Calcium Looping $(\mathrm{CaL})$ conditions for Thermochemical Energy Storage (TCES) in Concentrated Solar Power plants (CSP). Limestone samples have been calcined under different atmospheres and the resulting $\mathrm{CaO}$ has been characterized by means of XRD, $\mathrm{N}_{2}$ physisorption, $\mathrm{SEM}$, and particle size analysis. The multicycle $\mathrm{CaO}$ activity of the precalcined samples under CaL conditions for CSP energy storage has been studied by means of thermogravimetric analysis (TGA). Importantly, CaL-CSP energy storage conditions radically differ from those used for $\mathrm{CO}_{2}$ capture. The former involve carbonation at high temperature under high $\mathrm{CO}_{2}$ partial pressure and calcination under relatively low temperature in the absence of $\mathrm{CO}_{2}$ whereas the latter consist of 
carbonation under low $\mathrm{CO}_{2}$ partial pressure and calcination under high temperature and high $\mathrm{CO}_{2}$ partial pressure. Thus, previous works have shown that the multicycle conversion of $\mathrm{CaO}$ derived from natural limestone at $\mathrm{CaL}$ conditions for $\mathrm{CO}_{2}$ capture is mainly hindered by the drastic loss of $\mathrm{CaO}$ porosity and surface area available for fast carbonation due to enhanced sintering under harsh calcination conditions. On the other hand, our work shows that the multicycle $\mathrm{CaO}$ conversion at CaL-CSP energy storage conditions is rather limited by pore plugging, which is enhanced as $\mathrm{CaO}$ porosity and particle size are increased. Carbonation under high temperature and high $\mathrm{CO}_{2}$ partial pressure leads to a very fast building up of a thick $\mathrm{CaCO}_{3}$ layer in the fast reaction controlled stage. As a consequence, the small pore size caused by the mild calcination conditions favours pore plugging, which prevents $\mathrm{CO}_{2}$ to reach a relatively high $\mathrm{CaO}$ surface area by pore diffusion at the interior of the particles. Thus, pore plugging would be a detrimental phenomenon in the application of the CaL process to CSP energy storage especially if relatively large particles should be employed in practice. In our work, this phenomenon has been observed to be critical for particles of size on the order of tens of microns. This can be an important issue to be assessed for the use in pilotscale plants of circulating fluidized bed reactors, which usually require the use of particles of size on the order of hundreds of microns to avoid a significant loss of fine particles that cannot be recovered by conventional cyclones.

\section{Acknowledgements}

Financial support by the Spanish Government Agency Ministerio de Economia y Competitividad (contracts CTQ2014-52763-C2-2-R and CTQ2014-52763-C2-1-R) is acknowledged. The authors thank VPPI-US for the AP current contract and the RyC program for PESJ contract. The Microscopy, Functional Characterization and X-ray services of the Innovation, Technology and Research Center of the University of Seville (CITIUS) are gratefully acknowledged. 


\section{References}

(1) Framework Convention on Climate Change. Adoption of the Paris Agreement. Proposal by the President. 2015.

(2) Hinkley, J. T.; Hayward, J. A.; Curtin, B.; Wonhas, A.; Boyd, R.; Grima, C.; Tadros, A.; Hall, R.; Naicker, K. An analysis of the costs and opportunities for concentrating solar power in Australia. Renew. Energy 2013, 57, 653-661.

(3) Reddy, V. S.; Kaushik, S. C.; Ranjan, K. R.; Tyagi, S. K. State-of-the-art of solar thermal power plants-A review. Renew. Sust. Energ. Rev. 2013, 27, 258273.

(4) Zhang, H. L.; Baeyens, J.; Degreve, J.; Caceres, G. Concentrated solar power plants: Review and design methodology. Renew. Sust. Energ. Rev. 2013, 22, 466-481.

(5) Janz, G. J.; Allen, C. B.; Bansal, N. P.; Murphy, R. M.; Tomkins, R. P. T. Physical properties data compilations relevant to energy storage. II. Molten salts: data on single and multi-component salt systems. (No. NSRDS-NBS-61 (Pt. 2)). Rensselaer Polytechnic Inst., Troy, NY (USA). Cogswell Lab. 1979.

(6) Bauer, T.; Breidenbach, N.; Pfleger, N.; Laing, D.; Eckand, M. Overview of molten salt storage systems and material development for solar thermal power plants. In Proceedings of the 2012 National Solar Conference for (SOLAR 2012), Denver, 2012.

(7) Parrado, C.; Marzo, A.; Fuentealba, E.; Fernandez, A. G. 2050 LCOE improvement using new molten salts for thermal energy storage in CSP plants. Renew. Sust. Energ. Rev. 2016, 57, 505-514.

(8) Liu, M.; Tay, N. H. S.; Bell, S.; Belusko, M.; Jacob, R.; Will, G.; Saman, W.; Bruno, F. Review on concentrating solar power plants and new developments in high temperature thermal energy storage technologies. Renew. Sust. Energ. Rev. 2016, 53, 1411-1432.

(9) Pfleger, N.; Bauer, T.; Martin, C.; Eck, M.; Worner, A. Thermal energy storage overview and specific insight into nitrate salts for sensible and latent heat storage. Beilstein J. Nanotechnol. 2015, 6, 1487-1497.

(10) Paksoy, H. Ö., Thermal Energy Storage for Sustainable Energy Consumption: fundamentals, case studies and design, Springer Science \& Business Media, 2007. 
(11) Mahlia, T. M. I.; Saktisandan, T. J.; Jannifar, A.; Hasan, M. H.; Matseelar, H. S. C. A review of available methods and development on energy storage; technology update. Renew. Sust. Energ. Rev. 2014, 33, 532-545.

(12) Pardo, P.; Deydier, A.; Anxionnaz-Minvielle, Z.; Rouge, S.; Cabassud, M.; Cognet, P. A review on high temperature thermochemical heat energy storage. Renew. Sust. Energ. Rev. 2014, 32, 591-610.

(13) Wentworth, W. E.; Chen, E. Simple thermal-decomposition reactions for storage of solar thermal-energy. Sol. Energy 1976, 18, (3), 205-214.

(14) Sakellariou, K. G.; Karagiannakis, G.; Criado, Y. A.; Konstandopoulos, A. G. Calcium oxide based materials for thermochemical heat storage in concentrated solar power plants. Sol. Energy 2015, 122, 215-230.

(15) Chacartegui, R.; Alovisio, A.; Ortiz, C.; Valverde, J. M.; Verda, V.; Becerra, J. A. Thermochemical energy storage of concentrated solar power by integration of the calcium looping process and a $\mathrm{CO}_{2}$ power cycle. Appl. Energy 2016, 173, 589-605.

(16) Ortiz, C.; Chacartegui, R.; Valverde, J. M.; Becerra, J. A. A new integration model of the calcium looping technology into coal fired power plants for $\mathrm{CO}_{2}$ capture. Appl. Energy 2016, 169, 408-420.

(17) Avila-Marin, A. L. Volumetric receivers in Solar Thermal Power Plants with Central Receiver System technology: A review. Sol. Energy 2011, 85, (5), 891910.

(18) Berger, E. E. Effect of steam on the decomposition of limestone. Industrial and Engineering Chemistry 1927, 19, (1), 594-596.

(19) Sceats, M. G.; Horley, C. J. U.S. Patent No 8,807,993. Washington, DC: U.S. Patent and Trademark Office. (2014).

(20) Taketomo, E.; Fujiura, M. U.S. Patent No. 4,482,360. Washington, DC: U.S. Patent and Trademark Office. (1984).

(21) Blamey, J.; Anthony, E. J.; Wang, J.; Fennell, P. S. The calcium looping cycle for large-scale $\mathrm{CO}_{2}$ capture. Prog. Energy Combust. Sci. 2010, 36, (2), 260-279.

(22) Perejon, A.; Romeo, L. M.; Lara, Y.; Lisbona, P.; Martinez, A.; Valverde, J. M. The Calcium-Looping technology for $\mathrm{CO}_{2}$ capture: On the important roles of energy integration and sorbent behavior. Appl. Energy 2016, 162, 787-807.

(23) Valverde, J. M. Ca-based synthetic materials with enhanced $\mathrm{CO}_{2}$ capture efficiency. J. Mater. Chem. A 2013, 1, (3), 447-468. 
(24) Florin, N. H.; Blamey, J.; Fennell, P. S. Synthetic CaO-Based Sorbent for $\mathrm{CO}_{2}$ Capture from Large-Point Sources. Energy Fuels 2010, 24, 4598-4604.

(25) Valverde, J. M.; Perejon, A.; Perez-Maqueda, L. A. Enhancement of Fast $\mathrm{CO}_{2}$ Capture by a Nano-SiO $/$ CaO Composite at Ca-Looping Conditions. Environ. Sci. Technol. 2012, 46, (11), 6401-6408.

(26) Erans, M.; Manovic, V.; Anthony, E. J. Calcium looping sorbents for $\mathrm{CO}_{2}$ capture. Appl. Energy 2016, 180, 722-742.

(27) Valverde, J. M.; Sanchez-Jimenez, P. E.; Perez-Maqueda, L. A. High and stable $\mathrm{CO}_{2}$ capture capacity of natural limestone at Ca-looping conditions by heat pretreatment and recarbonation synergy. Fuel 2014, 123, 79-85.

(28) Sarrion, B.; Valverde, J. M.; Perejon, A.; Perez-Maqueda, L.; Sanchez-Jimenez, P. E. On the Multicycle Activity of Natural Limestone/Dolomite for Thermochemical Energy Storage of Concentrated Solar Power. Energy Technol. 2016, 4, (8), 1013-1019.

(29) Koga, N.; Criado, J. M. The influence of mass transfer phenomena on the kinetic analysis for the thermal decomposition of calcium carbonate by constant rate thermal analysis (CRTA) under vacuum. Int. J. Chem. Kinet. 1998, 30, (10), 737-744.

(30) Wang, Y.; Thomson, W. J. The effects of steam and carbon-dioxide on calcite decomposition using dynamic X-ray-diffraction. Chem. Eng. Sci. 1995, 50, (9), 1373-1382.

(31) Valverde, J. M.; Sanchez-Jimenez, P. E.; Perejon, A.; Perez-Maqueda, L. A. $\mathrm{CO}_{2}$ multicyclic capture of pretreated/doped $\mathrm{CaO}$ in the Ca-looping process. Theory and experiments. Phys. Chem. Chem. Phys. 2013, 15, (28), 1177511793.

(32) Valverde, J. M.; Sanchez-Jimenez, P. E.; Perez-Maqueda, L. A.; Quintanilla, M. A. S.; Perez-Vaquero, J. Role of crystal structure on $\mathrm{CO}_{2}$ capture by limestone derived $\mathrm{CaO}$ subjected to carbonation/recarbonation/calcination cycles at $\mathrm{Ca}$ looping conditions. Appl. Energy 2014, 125, 264-275.

(33) Xu, Y. Q.; Luo, C.; Zheng, Y.; Ding, H. R.; Zhang, L. Q. Macropore-Stabilized Limestone Sorbents Prepared by the Simultaneous Hydration-Impregnation Method for High-Temperature $\mathrm{CO}_{2}$ Capture. Energy Fuels 2016, 30, (4), 32193226. 
(34) Manovic, V.; Anthony, E. J. Thermal activation of CaO-based sorbent and selfreactivation during CO2 capture looping cycles. Environ. Sci. Technol. 2008, 42, (11), 4170-4174.

(35) Grasa, G. S.; Abanades, J. C. $\mathrm{CO}_{2}$ capture capacity of $\mathrm{CaO}$ in long series of carbonation/calcination cycles. Ind. Eng. Chem. Res. 2006, 45, (26), 8846-8851.

(36) Valverde, J. M.; Sanchez-Jimenez, P. E.; Perez-Maqueda, L. A. Limestone Calcination Nearby Equilibrium: Kinetics, $\mathrm{CaO}$ Crystal Structure, Sintering and Reactivity. J. Phys. Chem. C 2015, 119, (4), 1623-1641.

(37) Li, Z. S.; Fang, F.; Tang, X. Y.; Cai, N. S. Effect of Temperature on the Carbonation Reaction of $\mathrm{CaO}$ with $\mathrm{CO}_{2}$. Energy Fuels 2012, 26, (4), 2473-2482.

(38) Alvarez, D.; Abanades, J. C. Pore-size and shape effects on the recarbonation performance of calcium oxide submitted to repeated calcination/recarbonation cycles. Energy Fuels 2005, 19, (1), 270-278.

(39) Lu, H.; Reddy, E. P.; Smirniotis, P. G. Calcium oxide based sorbents for capture of carbon dioxide at high temperatures. Ind. Eng. Chem. Res. 2006, 45, (11), 3944-3949.

(40) Pinheiro, C. I. C.; Fernandes, A.; Freitas, C.; Santos, E. T.; Ribeiro, M. F. Waste Marble Powders as Promising Inexpensive Natural CaO-Based Sorbents for Post-Combustion $\mathrm{CO}_{2}$ Capture. Ind. Eng. Chem. Res. 2016, 55, (29), 7860-7872.

(41) Perez-Vaquero, J.; Valverde, J. M.; Quintanilla, M. A. S. Flow properties of $\mathrm{CO}_{2}$ sorbent powders modified with nanosilica. Powder Technol. 2013, 249, 443455. 